\title{
Psicólogos, excombatientes e intervención psicosocial: desnaturalizar la violencia en Colombia
}

\author{
Daniel Varela Corredor*
}

Entre agosto y diciembre de 2007 realicé una aproximación etnográfica al Programa de Intervención Psicosocial para la Reintegración de Excombatientes de Grupos Armados Ilegales en Colombia, dirigido por la Alta Consejería Presidencial para la Reintegración (ACR). Mi interés fue entender los sentidos implícitos de la política pública que orientaban la experiencia social de los excombatientes. Para lograrlo, revisé los marcos institucionales y jurídicos, los manuales e instrumentos de intervención, observé la labor de psicólogos intervinientes en visitas domiciliarias y talleres psicosociales y me entrevisté con algunos de estos intervinientes y con excombatientes intervenidos.

\footnotetext{
* Estudiante de la Maestría en Antropología e investigador del Centro de Estudios Sociales (CES) de la Universidad Nacional de Colombia. Miembro de los grupos "Estudios Afrocolombianos" y "Conflicto Social y Violencia". Correo electrónico: danielv_85@hotmail.com
} 
El objetivo de este texto es dar cuenta de algunas de las formas como se explica la violencia y se percibe al excombatiente en el interior de este programa de intervención psicosocial. Me pregunto cómo esas explicaciones marcan las relaciones cotidianas entre psicólogos intervinientes y desmovilizados intervenidos; pero al tiempo, cómo la cercanía de esas relaciones le permite al psicólogo reflexionar, cuestionar y transformar los presupuestos sobre violencia y violento que plantea el programa.

\section{Emociones y violencia en la intervención psicosocial}

¡La labor psicosocial es la encargada de propiciar en ustedes un correcto manejo de las emociones! (Varela, 2007).

Así fue como Camilo ${ }^{1}$, uno de los casi doscientos psicólogos contratados por el Programa de Reintegración en Colombia, explicó a un nutrido grupo de excombatientes el objetivo de los talleres psicosociales que cada ocho días, a esa hora y en ese lugar él dirigía. Acto seguido, ilustró su afirmación:

Solo miren el caso de hace unas semanas, cuando un muchacho del programa, con una cerveza en la cabeza, se exaltó a tal grado que sin pensarlo mató a una persona. Por eso les digo que es necesario aprender a tener autocontrol de uno mismo [...] Ustedes me han contado que en momentos de conflicto o choque con personas retornan sentimientos propios de la guerra: sentimientos de destruir al otro [...] En momentos de tensión vuelven a salir imágenes y sentimientos del campo de batalla; cosas que se decían allá, se vuelven a decir aquí. Así, cuando tenemos cualquier problema con alguien, lo emocional nos traiciona y no nos hace conscientes de nuestros actos; entonces, actuamos de forma violenta (Varela, 2007).

1 El nombre personal del interviniente ha sido modificado por el seudónimo "Camilo" para favorecer su seguridad y por petición de él mismo. También son seudónimos los nombres de algunos desmovilizados que se nombran a continuación. 
Camilo presume que la combinación en el ser excombatiente de una historia de profundo dolor propia de la guerra y el "incorrecto manejo de sus emociones" crea la tendencia a generar en ellos un desafortunado coctel que amenaza explotar de manera arbitraria. Para nuestro psicólogo, la actitud violenta del sujeto desmovilizado, expresada en su participación en la guerra, tiene que ver con el descontrol emocional interno de cada uno de ello, esto es, una tensión no resuelta entre instinto y razón que irreflexivamente los arrojó a participar de grupos armados ilegales.

Recordé entonces un capítulo de los manuales de intervención psicosocial, que la ACR produjo para apoyar la labor que Camilo y otros psicólogos adelantan. Las emociones, según este manual,

se encuentran ubicadas en el cerebro más primitivo, denominado cerebro reptíleo, encargado de la manifestación de los instintos básicos de supervivencia. En este cerebro se encuentra el centro encargado de controlarlas, denominado la amígdala. Como las emociones son producidas por ideas, recuerdos, vivencias, deseos y pasiones y siempre vienen acompañadas por cambios corporales o del estado de ánimo, se requiere de una interacción con la corteza cerebral para lograr su control, pues es allí donde se integran las habilidades cerebrales superiores y más complejas de la mente humana [...] Del correcto manejo [de las emociones] pueden derivarse habilidades como el control de impulsos, la autoconciencia, la motivación, la empatía [...], y rasgos de carácter como la autodisciplina, la compasión o el altruismo, indispensables para una sana adaptación social [negritas agregadas] (Programa de Paz y Reconciliación, 2007, p. 79).

También recordé lo acontecido en una de las pasadas sesiones de taller psicosocial, donde Camilo propuso a los desmovilizados asistentes la actividad titulada "El juego de la vida": 
¡El objetivo del juego es obtener el máximo puntaje posible! El grupo de desmovilizados se dividirá en cuatro grupos: A, B, C, D; en donde A jugará con C, y B jugará con D. Existen cinco jugadas, en las cuales cada grupo deberá tomar la decisión de votar "rojo" o "verde". El voto del grupo se contrastará con el voto del grupo con el cual le correspondió jugar: A con C, y B con D. Según ello, se define el puntaje que cada grupo obtuvo por cada jugada. Así, hay tres posibilidades de marcador: 1. Si ambos equipos votan "verde", ambos obtendrán +3 puntos; 2. Si ambos equipos votan "rojo", ambos obtendrán -5 puntos; 3. Si el equipo A vota "rojo" y el equipo C vota "verde", A obtendrá +5 puntos y C obtendrá -3 puntos (Varela, 2007).

Camilo dio la oportunidad a cada grupo para discutir en privado y definir una estrategia. Luego de ello dio el pitazo inicial y cada equipo comenzó a votar. El psicólogo llevaba una tabla de puntajes en el tablero, con el fin de "imprimirle mayor emoción al juego". Esta tabla ayudó a los equipos a entender mejor la compleja dinámica de marcadores y puntajes y, por tanto, a que se decidieran a ganar. Los desmovilizados habían entendido el juego como una competencia entre los equipos designados por Camilo; por ello, sus mayores decisiones de voto se orientaron por el color rojo, esperando que su contrincante votara "verde" y obtuviera así una ventaja considerable. Quizá eran conscientes del riesgo que corrían si los dos equipos votaban "rojo": ambos restarían cinco puntos a su total; sin embargo, en la sumatoria absoluta dicho marcador no los perjudicaba, pues implicaba un empate técnico: valía la pena arriesgarse y ganar. La tabla final de puntuación que mostró Camilo fue la siguiente:

\begin{tabular}{|c|c|c|c|c|c|c|}
\hline Grupo & Jugada 1 & Jugada 2 & Jugada 3 & Jugada 4 & Jugada 5 & Puntaje total \\
\hline A & Verde & Rojo & Rojo & Rojo & Rojo & -7 \\
\hline B & Rojo & Rojo & Rojo & Verde & Rojo & -3 \\
\hline C & Verde & Verde & Rojo & Rojo & Rojo & -15 \\
\hline D & Verde & Verde & Rojo & Rojo & Rojo & -11 \\
\hline
\end{tabular}

Fuente: Varela (2007) 
Al término del juego, el psicólogo intervino:

Este juego está diseñado para que cada equipo obtenga 15 puntos y entre todos sumen 60 . Ustedes ni siquiera sumaron, sino que restaron -36. Yo les dije que el objetivo del juego era obtener el máximo puntaje posible, pero ustedes jugaron a que el otro obtuviera el mínimo [...] ¿Qué pasa en nuestra cultura para que el A con $\mathrm{B}$ se vuelva A contra B? ¿Por qué no podemos controlar el instinto de competencia y detenernos a pensar qué es lo que realmente nos conviene? [...] Lo que se buscaba con este juego era que se comportaran como una sociedad, en donde la jugada de cada grupo fuera pensada en beneficio de todos y no solo personal [...] La emoción del juego fue lo que los hizo no tener conciencia de eso [...] ¿En qué se les parece esto a la vida? [...] Definitivamente es una cultura que nos envuelve a todos; les pasó a ustedes allá en la guerra, pero también les pasa aquí, y es germen de un sinnúmero de conflictos. ¿Qué implica el reto de plantearse una sociedad? Precisamente eso: construir conciencia de que cualquier cosa que hagamos debe ir en beneficio de todos y no del personal; eso es lo que en psicología llamamos "prosocialidad" (Varela, 2007).

Camilo confirmaba que tenía ante sí a unos sujetos víctimas de sus emociones, culturalmente incapaces de pensar en el bien común y comportarse como sociedad. Los desmovilizados, para el psicólogo, se encontraban presos de un instinto que, como la competencia, en el pasado los arrojó a participar en grupos armados ilegales y ahora amenazaba con irrumpir en la ciudad. Los manuales de intervención, por su lado, le ayudaban a explicar el comportamiento violento como propio de estados inferiores de evolución, marcados por la predominancia del "cerebro reptil" y sus impulsos emotivos. El que los desmovilizados lograran el control de estos impulsos -y con ello una "sana adaptación social" - era la tarea que el gobierno le había encomendado a Camilo y a otros psicólogos. 
Ahora bien, ¿qué pretende este discurso de las emociones? ¿Qué implica en las relaciones entre Estado, sociedad y excombatientes? ¿Qué sentido le imprime a la intervención psicosocial y al trabajo de los psicólogos como Camilo?

"Emociones" es una de las categorías que usa el modelo de intervención psicosocial para explicar el fenómeno de la guerra en Colombia. Mediante este concepto, la Agencia Colombiana para la Reconciliación (ACR) limita las causas de la violencia a las patologías psíquicas de algunos individuos y, por consiguiente, declara que la psicología clínica es la ciencia llamada a promover una solución. Este presupuesto es problemático porque argumenta que el conflicto armado solo responde a impulsos individuales y que nada tiene que ver con la estructura de las relaciones sociales y políticas del país. Además legitima el orden social establecido y aísla al Estado colombiano de cualquier responsabilidad histórica sobre la guerra, dándole potestad para intervenir, por medio de psicólogos, la interioridad de los sujetos sociales.

Los excombatientes son marcados como sujetos sin conciencia de sus actos y peligrosos para la sociedad. En un texto anterior, Varela (2010) explora las implicaciones sociales que estas marcas traen cuando por causa de esa supuesta "inconciencia" de los actos se desprecia el conocimiento que el excombatiente ha podido acumular sobre las dinámicas, causas y coyunturas del conflicto armado. Este conocimiento se valora cuando aporta a labores de inteligencia militar y ayuda a acertar golpes estratégicos a organizaciones insurgentes, pero se hace a un lado cuando aporta a políticas de prevención y salida política a la guerra, o incluso cuando aporta al proceso de desarme, desmovilización y reintegración.

Mediante el estigma de "peligrosos", las experiencias de los excombatientes son acalladas en la esfera de la sociedad y recluidas en los espacios terapéuticos del taller psicosocial, en tanto se constituyen en relatos traumáticos de los que el sujeto debe despojarse para iniciar una nueva vida (Varela, 2010, 
p. 114). El psicólogo termina siendo el único no excombatiente que en el marco del Programa Institucional tiene la oportunidad de convivir con excombatientes, escuchar varios de sus relatos y reflexionar sobre estos. Me pregunto, entonces, por las implicaciones que el discurso de las emociones trae a las relaciones entre psicólogo y desmovilizados, al igual que por el conocimiento que los psicólogos intervinientes producen al entrar en contacto cotidiano con población excombatiente.

Aquella tarde de taller en que Camilo les definió a los desmovilizados la labor psicosocial como "la encargada de propiciar [...] un correcto manejo de las emociones", también les explicó algunos cambios operativos que a partir del siguiente mes se implementarían en el Programa de Reintegración. Estos cambios obedecían al traslado administrativo del programa del Ministerio del Interior a la Alta Consejería para la Reintegración (Pearl, 2007). El nuevo programa, en comparación con el anterior del Ministerio del Interior, igualaba a $\$ 400.000$ pesos el valor de los apoyos monetarios mensuales para desmovilizados individuales y colectivos ${ }^{2}$, cuando antes algunos recibían casi un millón de pesos. De igual forma, el nuevo programa condicionaba dichos apoyos a que el desmovilizado asistiera semanalmente al taller psicosocial y estuviera matriculado en programas de bachillerato y de educación para el trabajo. Estas condiciones le complicaban la vida a la población beneficiaria, pues les restringía el tiempo para emplearse.

Naturalmente, las nuevas noticias acaloraron los ánimos entre los desmovilizados. Los murmullos invadieron el salón, mientras Camilo explicaba las nuevas reglas. Juan, un desmovilizado, se puso de pie y con voz fuerte lo interrumpió: "Yo francamente no entiendo nada, a uno aquí no le cumplen los derechos que ya se ganó. ¡Que me cumplan lo que yo firmé en mi entrega!". Camilo le refutó: "Tranquilo, hombre, el programa le

2 Los desmovilizados individuales son aquellos que abandonan un grupo armado por su voluntad, sin necesidad de que el grupo se desmovilice por completo. La desmovilización colectiva está vinculada a procesos de paz y supone la desarticulación por completo de un grupo. En el programa del Ministerio, los individuales recibían mensualmente hasta casi un millón de pesos, mientras los colectivos solo trescientos mil. 
va a cumplir, solo le pide que piense en su futuro y se prepare para un trabajo" (Varela, 2007).

Otro desmovilizado dijo:

¡Nosotros venimos del campo y allá para saber si una gallina tiene moquillo no tuvimos que ir a la Harvard! Necesitamos es que nos den nuestros proyectos productivos ${ }^{3}$ y que nos apoyen para volver al campo, que es de lo que nosotros sabemos (Varela, 2007).

\section{Camilo respondió:}

¡Entonces si sabe tanto, vaya al SENA a que lo certifiquen, y entonces ahí sí pida su proyecto! (Varela, 2007).

\section{Juan volvió a interrumpir:}

Aquí a uno no le respetan los derechos. Este programa es un fracaso. ¿Usted sabe cuántos grupos están formando los paramilitares? Allá donde estaban los cadáveres de los diputados ${ }^{4}$ está lleno de esos grupos. Pero eso a ustedes no les importa. El que se va, se va callado (Varela, 2007).

El ambiente se tornaba tenso. Camilo se acercó a Juan, subió el tono de su voz y levantando su brazo le advirtió:

Mire, maestro, si se quiere ir otra vez pa’ la guerra, ¡váyase!, aquí nadie lo está obligando a quedarse; es su vida [...] El compromiso que ustedes

3 Además del apoyo económico mensual que el desmovilizado recibe del programa, mientras se adapta a su nueva vida, el Gobierno promete al que abandone un grupo armado la inversión inicial para el establecimiento de un negocio. Esto recibe el nombre de "proyecto productivo". Debido al descalabro financiero de estos proyectos, la ACR impuso mayores restricciones para estos desembolsos e incluso definió que no todos los participantes del programa podrían aspirar a este tipo de apoyo.

4 Se refiere a los cadáveres de los diputados del Valle del Cauca, secuestrados en Cali por las Farc en el 2002 y asesinados en cautiverio en 2007. 
adquirieron aquí no fue ni con su tutor ni con el programa. Fue un compromiso con ustedes mismos y con su familia. Fue un compromiso con su futuro. Ahora, si quieren dejar eso botado por unos pinches pesos, háganlo, nosotros no podemos hacer nada, ni nos vamos a arrodillar a decirle: “¡Ay, por favor, no lo haga!” (Varela, 2007).

Gustavo, otro desmovilizado, comentó desde el otro extremo del salón: "Pero es que nosotros no estuvimos ahí por gusto. Fue por necesidad, y si la necesidad nos vuelve a llevar, pues ¿qué podemos hacer?" (Varela, 2007).

Finalmente, y para dar por terminada la sesión de taller, Camilo les dijo a todos:

Psicosocial es un espacio para crecer; yo como tutor simplemente debo acompañarlos en ese proceso. Aparte de esto, están las actividades de orden administrativo de la ACR, y lo que más les interesa a ustedes: los pagos. Yo como tutor certifico cuál es su compromiso con el proceso, y de esa manera autorizo los pagos; pero simplemente los autorizo, no tengo la potestad para modificar las políticas. A mí no me digan nada, porque yo no puedo hacer nada, simplemente les informo (Varela, 2007).

Algunos días después Camilo me confesó que aquella tarde de taller él había sentido miedo:

Daniel, es que no crea, todo ese resentimiento que se almacena en ellos estalla en forma de ira cuando uno menos se lo espera [...] Uno nunca sabe cuando la situación esté controlada o no. Pero yo le quiero pedir disculpas a usted, porque no actué como debí haber actuado; me dejé llevar por la tensión de sentirme en peligro, por el miedo, y entonces me salí de mis casillas. Siento vergüenza también con ellos, porque de pronto fui grosero (Varela, 2007). 
Me pregunté entonces por qué le avergonzaba a Camilo haberse dejado llevar por el miedo. ¿Era vergüenza de no haber sido un buen burócrata, al no alejarse de factores emocionales que limitan la neutralidad clínica de la intervención psicosocial? ¿Era vergüenza de que al haberse visto envuelto en ese miedo, en esas emociones, se dio cuenta de que se parecía más a ellos de lo que él pensaba? Finalmente me dijo:

El miedo es una cosa muy verraca, es lo que tiene en jaque a este programa. Cada tres meses hay renuncias masivas de psicólogos, ¿y todo por qué? Porque tienen miedo, y los desmovilizados se aprovechan de esto para intimidarlo a uno.

En efecto, varios tutores habían recibido amenazas por parte de desmovilizados, presionándolos por las firmas que estos cada mes deben emitir a la ACR, para certificar la asistencia de cada participante a los talleres y a los programas de estudio. Con esto, la ACR autoriza el pago del apoyo económico. "Si ve, el miedo es lo que tranca este proceso".

\section{Psicólogos y producción de saberes en la práctica}

Varias semanas después de los sucesos narrados en el acápite anterior, Camilo se preparaba para realizar un nuevo taller psicosocial; uno de tantos a los que asistí durante mi trabajo de campo. Él tenía a su cargo dos de las localidades más grandes de Bogotá; en cada una realizaba por lo menos dos talleres semanales, buscando horarios convenientes para todos los participantes. Ese día, por compromisos extraordinarios, Camilo aplazó la sesión de taller hasta las horas de la noche. Cuando el psicólogo me llamó a informarme el cambio de hora, también me ofreció su carro para irme y devolverme. En el camino de ida, mientras conversábamos sobre mi trabajo de investigación, Camilo me comentó: 
El modelo de intervención que propone la ACR es muy psicológico. Yo soy psicólogo, pero debo advertir que los psicólogos a veces tendemos a ser muy teóricos, muy abstractos. Una cosa es la teoría y otra distinta es lo que uno ve cuando está enfrentado a la manera de pensar y comportarse de estos muchachos. Uno es el que debe aprender a entenderlos, para así llegarles. Eso a uno el manual no se lo dice (Varela, 2007).

Le pregunté entonces sobre qué tanta autonomía tenía para rediseñar o proponer nuevas metodologías en sus talleres. Camilo me contestó:

¡Nula! La ACR propone el modelo y lo contrata a uno simplemente para que lo ponga en práctica. Lo que pasa es que este señor Gaviria ${ }^{5}$, quien trajo el modelo desde Medellín, tiene el capricho académico de demostrar que su propuesta sirve para toda Colombia. Pero es muy distinto como lo ve uno, que es el que está en contacto con ellos todo el tiempo. Las condiciones de Medellín son muy distintas a las de Bogotá. Allá se trataba de actuar sobre muchachos nacidos allí, en las comunas, y con desmovilizados colectivos, es decir, que no tenían el problema de inseguridad que aquí tienen los individuales. Además, muchos de los muchachos que están en Bogotá nunca antes habían pisado una ciudad (Varela, 2007).

La asistencia al taller fue significativamente baja: solo cuatro participantes se animaron a ir bajo la lluvia y el frío de la noche. Esto se prestó para que la sesión, que se proponía tocar el tema de la familia, transcurriera más como un diálogo entre los cuatro desmovilizados, Camilo y yo. El psicólogo nos preguntó, a los excombatientes y a mí, por nuestras historias familiares. Cuando Eduardo, excombatiente de las Farc proveniente de Barrancabermeja, hablaba sobre su padre, Camilo lo interrumpió: “¿A

5 Se refiere a Jorge Fernando Gaviria Vélez, psicólogo, director general del Programa Paz y Reconciliación de la Alcaldía de Medellín y actual docente y asesor de la Unidad de Reintegración Social de la ACR. Véase http://jorgegaviria.blogspot.com/2009/04/jorge-fernando-gaviria-velez.html 
usted como papá qué le gustaría repetir del suyo?’. Eduardo dio una respuesta que sorprendió a Camilo: "La educación, porque mi papá sí nos enseñó que nunca, nunca, nunca fuéramos a robar; que de mi hija digan 'ahí va esa puta', pero nunca 'ahí va esa ladrona”" (Varela, 2007).

“¿Usted pone a los ladrones en el último escalafón de la jerarquía social?", preguntó el psicólogo. El desmovilizado respondió: "Sí, ellos son un problema, junto con otros antisociales como los marihuaneros y los violadores". Luego, refiriéndose a los tiempos en que estuvo reclutado en la guerrilla, advirtió: "Ladrones, marihuaneros y violadores, si vuelvo a tener el poder, los vuelvo a matar". Los otros tres desmovilizados que nos acompañaban esa noche asintieron diciendo: "Sí, es que esa es la única solución" (Varela, 2007).

A Camilo le inquietaba la facilidad con que estos individuos declaraban la necesidad de eliminar a otros, y les preguntó por sus razones. Los cuatro desmovilizados, que pertenecieron tanto a ejércitos guerrilleros como paramilitares, hicieron alusión a su "ideología”. Camilo interrogó sobre a qué ideología se estaban refiriendo: "A la del grupo", respondieron con naturalidad. Camilo se mostraba consternado: ninguno de los desmovilizados sentados esa noche en la mesa toleraba la idea de compartir el mundo con esa clase de individuos (ladrones, marihuaneros y violadores), a quienes culpaban de muchos de los problemas del país. No demoró en decirles: "Ustedes lo que tienen es delirio de justicieros; quieren hacer justicia por sus propias manos e ignoran los procedimientos que tiene el Estado aquí en la vida civil”. Eduardo contestó: “¡Eso no es hacer justicia, es poner orden!” (Varela, 2007).

El psicólogo, entrenado en los manuales y categorías que impone el modelo de intervención para la reintegración, pudo haber pensado que lo que estaba viendo no era más que el instinto violento incontrolado que emergía de dicha clase de sujetos. ¿Qué hacer? Camilo intentó cuestionarlos desde la misma situación que como desmovilizados ellos vivían en la ciudad: 
Ustedes han sido capaces de mirar en contexto sus acciones; incluso a veces justifican su participación en la guerra por las circunstancias que entonces vivían: "que no tenían alternativa", "que la vida los condujo", "que ese era el mundo que desde pequeños les tocó vivir", y eso es algo que yo no les cuestiono. Pero, entonces, ¿serían ustedes capaces de mirar en contexto las circunstancias que ese otro ladrón, marihuanero o violador vivió para caer en ese túnel? (Varela, 2007).

A esto los desmovilizados contestaron negativamente:

Nada justifica que uno caiga en eso. Yo no sé si fue falta de educación o el que nace malo ya está predestinado. Pero el hecho es que ellos son una plaga que hay que eliminar de la forma más efectiva. A la culebra se le mata por la cabeza, y si la culebra acá es el robo, la violación o el vicio, hay que matar ese problema de raíz; y si no lo hace el Estado, pues le toca hacerlo a los grupos armados o al que no le dé miedo. Uno ya no puede porque acá en la ciudad es complicarse la vida, pero créame que si pudiera, lo haría (Varela, 2007).

El rostro de Camilo se debatía entre la inquietud y el horror. Para él, nada justificaba sus palabras, y expresando su inconformidad con ese principio de juicio les dijo:

Uno como psicólogo se mete a estas carreras a trabajar con dolor humano; pero uno siempre cree que a esas personas es posible transformarlas, hacer que su vida florezca. Para mí es ofuscante, espero que me entiendan, que a un ladrón haya que eliminarlo, que no tenga derecho siquiera a la oportunidad de cambiar. Así como ustedes dicen que detestan los ladrones, los marihuaneros y los violadores, en la sociedad hay personas que en este momento están diciendo "yo odio a los desmovilizados, y si veo uno lo mato”. ¿Frente a eso, ustedes que tienen para decir? (Varela, 2007). 
Los desmovilizados simplemente asintieron, diciendo que era cierto, y que por tal razón el haber estado en la guerra debe guardarse a manera de secreto. Pero además remarcaron una diferencia entre ellos (los desmovilizados) y los otros (los ladrones), lo que consideraban un equívoco en el racionamiento de Camilo: "Es que su error [refiriéndose a Camilo] está en pensar que ese tipo de personas todavía se pueden cambiar. Esos ya están dañados, es un vicio que tienen y nunca lo van a dejar" (Varela, 2007). Por el contrario, asumían que su vida era un ejemplo de cómo el desmovilizado sí estaba dispuesto a cambiar. Para Camilo, estas palabras solo demostraban que la transformación aún estaba pendiente.

Luego del taller, en el transcurso de regreso tuve la oportunidad de hablar con él de lo acontecido esa noche. Camilo dijo:

De esta sesión salgo consternado. Creer que el otro es malo por naturaleza y que es necesario eliminarlo es una posición muy fascista. Sin embargo, creo que la sesión sirvió para encontrar la línea dura sobre la que hay que actuar; también creo que me mostró que a su transformación no nos hemos acercado ni a los tobillos. La prueba está en que ellos no cedieron ni poquito (Varela, 2007).

Posteriormente, quedándose pensativo y evocando algunas imágenes en su mente, me relató una experiencia de cuando le realizó la visita domiciliaria ${ }^{6}$ a un desmovilizado de las AUC, cuya historia asociaba directamente a lo acontecido esa noche:

Cuando entré al cuarto, lo primero que me impactó fue una bandera de Colombia extendida y en el centro las siglas AUC; además, el cuarto estaba lleno de fotos de recortes de prensa haciendo referencia al mismo grupo y algunas fotos de cuando él operaba en las filas. Todo el cuarto

6 Además de los talleres psicosociales semanales, cada psicólogo tutor debe monitorear los procesos individuales de 120 desmovilizados. Este monitoreo incluye visitas periódicas a los domicilios de residencia. 
era un homenaje a las Autodefensas Unidas de Colombia. Sin embargo, lo que más me dio certeza de que su mente no había todavía abandonado la ideología de muerte del grupo fue cuando le pregunté por las razones de la crisis depresiva en la que se encontraba sumido. El individuo al comienzo fue reacio a hablar, pero después de un tiempo de yo insistirle, llorando me contó: todo se debía a que él, antes de entrar al grupo, había sido ladrón de motocicletas, y que ahora le era imposible convivir con ese hecho. Nunca se lo había perdonado y nunca se lo iba a perdonar. A veces, decía él, sentía ganas hasta de matarse por ladrón (Varela, 2007).

\section{Sobre esta anécdota, Camilo comentó:}

En ese momento yo no entendía nada. ¿Cómo un posible actor de las más monstruosas masacres podía sentir remordimiento tan solo por haber robado motocicletas? Sin embargo, ahora, después de esta sesión, entiendo mejor las cosas. Daniel, acuérdese que los muchachos esta noche hacían referencia a su "ideología", es decir, a la del grupo armado; la misma ideología que profesaba el muchacho que le cuento con su altar a las AUC. Este programa no se ha detenido a pensar en eso. A nadie acá se le ha ocurrido entrar a estudiar más a fondo los grupos armados por dentro y cómo estos influyen en el comportamiento de los muchachos. El programa cree que ese comportamiento violento solo tiene que ver con su perfil psicológico; pero mire, ¡también tiene que ver con su historia de paso por el grupo armado! [...] ¿Cómo hacer para que los desmovilizados se den cuenta de que eso es aprendido, de que no es natural? ¿Cómo apelar a sus conciencias y a su sentido común? ¿Cómo demostrarles que cuando pequeños ellos no pensaban así? (Varela, 2007).

El desconcierto de Camilo con lo acontecido esa noche de taller, más su experiencia de visita domiciliaria a un desmovilizado de las AUC, lo llevó a 
iniciar un proceso reflexivo que cuestionaba los principios conceptuales del Programa de Reintegración, lo que previamente he llamado "el discurso de las emociones". Fue evidente para él que las explicaciones de la acción violenta tenían que ver más con su paso por el grupo que con un natural instinto agresivo; que la violencia en ellos no era tan natural como la asumía el modelo de intervención psicosocial, sino que era producto de aprendizajes íntimamente relacionados con su historia en las organizaciones armadas. Con la pregunta "¿cómo hacer para que los desmovilizados se den cuenta de que la violencia es aprendida?", Camilo interpelaba a los desmovilizados pero también al programa, llamando la atención sobre la necesidad de estudiar detenidamente las formas de socialización y aprendizaje en el interior de las organizaciones armadas; en últimas, estudiar esa "ideología" a la que los desmovilizados apelaron esa noche.

El paso de creer en una "violencia natural" a creer en una "violencia aprendida" o "modelada" dentro de un grupo armado cuestiona la imagen de sujeto que el modelo de intervención de la ACR y el mismo Camilo habían previsto: la de aquel sujeto primitivo y reptil dominado por sus impulsos emocionales. Ahora para Camilo el desmovilizado era un sujeto con "sentido común" al cual apelar, y con una historia de violencia previa, marcada por formas de socialización y aprendizajes.

\section{Referencias}

Pearl, F. (2007, 22 de agosto). Grabación de la rendición de cuentas de la Presidencia de la República (debate televisado). Canal Institucional.

Programa Paz y Reconciliación (2007). Del individuo al colectivo, de la persona a la ciudadanía: manual de intervención psicosocial para la reinserción. Alcaldía de Medellín: Agencia de los Estados Unidos para el Desarrollo Internacional (USAID). 
Varela, D. (2007, agosto-noviembre). Diarios de campo de observación etnográfica en talleres psicosociales de la ACR (documento inédito). Bogotá: Universidad Nacional de Colombia.

Varela, D. (2010). Cuando el intervenido interpela la intervención. Excombatientes de grupos armados ilegales en proceso de reintegración. En Mosquera, C., Martínez, M. y Lorente, B. (Ed.). Intervención social, cultura y ética: un debate interdisciplinario. Bogotá: Universidad Nacional de Colombia. 